\title{
Individualized Teaching Design and Implementation Strategy under Network Environment
}

\author{
Xin $\mathrm{He}$ \\ Hunan International Business Vocational College, Changsha, 410201, China
}

Keywords: Network, Individualized teaching, Implementation

\begin{abstract}
With continuous improvement to network information, information communication channels become richer and more diversified, which provides strong technical supports for individualized teaching. At present, individualized teaching has huge influence on educational circles. On this basis, this paper analyzes the connotation of individualized teaching and relevant advantages. Moreover, this paper also proposes design and implementation strategies based on network individualized teaching.
\end{abstract}

\section{Introduction}

Network environment platform can enrich network teaching design of teachers. To some extent, it can also structure an independent choice framework for students. Under this multi-layer and multi-dimensional framework, learning needs of different learners can be satisfied. Each student can select the optimal mode to learn different contents at the optimal learning time according to actual conditions.

\section{Meaning of Individualized Teaching}

\section{Connotation of individualized teaching}

Individualized teaching refers to the mode of teaching showing respect to the students' individualities and aiming at different individualities, specialties and needs of different students. Its teaching mode mainly includes "several-to-one" and "one-to-one". Considering certain differences between different students, teachers must provide the students with diversified learning contents and methods under independent choice in the teaching process. Besides, the core of individualized teaching lies on variation with each individual and teaching in accordance with their aptitudes [1].

\section{Connotation of individualized teaching under network environment}

For individualized teaching under network environment, strong information technology is used in combination to realize resource sharing and mutually aided teaching according to actual conditions and learning needs of different students, so as to give better assistance and support to the students and guarantee that each student can enjoy individualized teaching in the entire learning process.

\section{Several Advantages of Individualized Teaching}

Develop teaching design and meet the learners' need according to the characteristics of individual learners

Prior to the development of teaching activities, teachers should have relevant teaching designs. In the design of individualized teaching, such teaching designs must be more exquisite or even detailed to the determination of a learner's learning objective and design process of his/ her learning program. To further satisfy the learners' needs, teachers must start with the personalities of individual learners, master their characteristics and develop teaching designed in a scientific way. From the perspective of experience, this is more consistent with the learners' learning mode. From the perspective of the 
constructivism learning theory, this can give better assistance to the students in constructing a high-efficiency cognitive system.

\section{Intensify feedback between learners and learning supporters, and further improve teaching quality}

On the one hand, individualized teaching can strengthen interactions between learners and learning supporters. On the other hand, individualized teaching can enhance the active atmosphere of teaching activities. If the atmosphere of teaching activities is too depressed or too active, it is unfavorable for learning. Learning supporters should make relevant adjustment. Thus, it can feed back learning effect in a more direct way, so as to improve teaching quality.

\section{New relationship between students and teachers with good interaction is helpful for enriching learning resources.}

Teachers should implement individualized teaching, pay more attention to deep demands of learners, change traditional relationship between students and teachers, and form a new kind of relationship between students and teachers (i.e. good-interaction relationship). This is a kind of good-interaction relationship, which highlights an exploratory relationship under mutual establishment and perfection of the cognitive system. At the same time, both learners and learning supporters are beneficial from the good-interaction relationship [2]. At least, learners can provide, as case teaching strategy, teaching resources to learning supporters. In this interactive process, exchange costs for teaching activities can be reduced to a large extent.

\section{Design and Implementation Strategies of Individualized Teaching under Network Environment}

\section{Utilize network courses for individualized teaching}

For learners and learning supporters, network course can play several roles. As a virtual learning environment, it can provide a learning platform for learners so that the learners can get necessary learning resources. At the same time, network course can also be used as a carrier for learning courses of the learners. For learning supporters, it provides individualized learning design programs according to specific needs and characteristics of individual students. In the learning process of network courses, learners can select necessary resources in the optimal learning time according to individualized guidance provided by learning supporters, so as to autonomously and orderly finish relevant learning tasks with a reasonable learning schedule.

\section{Guiding principles of network individualized teaching}

Definite objective and strong pertinence: teachers should make a reasonable survey on various conditions of learners (such as knowledge level, learning capacity and learning needs), make individualized design on teaching management mechanism and process of network teaching platform, pay more attention to teaching effectiveness, and realize teaching in accordance with aptitudes of different students.

Scientific, orderly and reasonable interface design: rich and individualized learning interfaces can attract learners' attention, provide different learning support services to the students, and allow students to independently reorganize learning resources according to these hobbies ${ }^{[3]}$. At the same time, platform interface must enrich interactive means, meet interactive exchange between students and teachers, between teachers and teachers and between students and students, make the learning environment more interactive, make students and teachers in different places feel as if they entered a virtual learning atmosphere and space, enable teachers to organize and guide learners' learning activities.

Complete, scientific and reasonable evaluation mechanism: it is essential for a scientific and reasonable evaluation mechanism. Generally, it covers the following four aspects of contents: the 
first one is a student-related evaluation mechanism. The second one is a teacher-related evaluation mechanism. The third one is an evaluation mechanism related to learning effects and learning resources. The fourth one is an evaluation mechanism related to network platform. In the evaluation, importance must be also attached to justice as well as rewards \& punishment.

Distributed design on digital learning resource management platform and network learning platform: management of teaching process is the principal function of network learning platform. Management of learning resources is the principal function of learning resource management platform. Functions of both platforms are independent from each other. In the design of digital learning resource management platform, it is necessary to have a group of standard interfaces. Thus, multiple network learning platforms can be developed under this platform, so as to meet diversified network teaching needs.

\section{Establish a multi-function network course platform}

Function of online teaching: for students, realization of online teaching function can enable the students to independently select courses and teachers in the platform. Moreover, it can also enhance interactive exchange between students and teachers. For teachers, the function of online teaching can help them to allocate and correct homework, perform online answering, regularly track the students' learning conditions, and apply multimedia teaching.

Function of teaching resource management: for teachers, the function of teaching resource management can help them to release and manage teaching resources at any time and place and remarkably improve teaching management efficiency. At the same time, the students can also obtain necessary learning resources at any time and place.

Function of student system management: the student system management has many functions, mainly including registration, online student statistics and course management.

\section{Design strategies of network course teaching}

Resource sharing: in this module, teachers can upload numerous resources, such as classroom explanation, teaching video and courseware. Moreover, teachers can also upload the third party resources into this module for reference of students and other teachers. Therefore, this part must be provided with a super-volume memory space. Moreover, it should be also featured by real-time updating and long-term stability. This module can also realize uploading downloading and storage of resources, so as to realize resource sharing.

Mutually aided teaching: generally, online communication is realized through forum. In the forum, interactive communication can be made between students and students or between students and teachers. In the same forum, learners can exchange learning methods with each other, and summarize learning experiences together. Teachers can also answer questions on the Internet. In most cases, online answering includes two modes: automatic answering and manual answering. In the mode of automatic answering, the system will find our key words and then intelligently search in the knowledge base and the question base after students remotely submit question descriptions through network. Then, the system will represent relevant answers. If the system failed to search for relevant answers, it will automatically send the question to the teacher's voicemail box. After the teacher answers this question, the system will send hint to the student. In the mode of manual answering, a student can directly send his/ her question to the teacher. After the teacher answers the question, the answer will be timely sent to the student.

Independent learning: on the student client-side, students can make self perfection to their learning objectives and schedules through online teaching and network teaching resources. Through network teaching platform, students can also feed back their questions to teachers. However, teachers will answer the students' questions through this platform ${ }^{[4]}$. Additionally, students can also utilize the platform for online exercises and tests as well as practice tests. 


\section{Several key factors for implementation of individualized teaching}

On the one hand, teachers should comply with regular teaching rules and ordinary teaching preparation steps in the process of developing individualized teaching activities. On the other hand, teachers should have special quality and requirements, and follow the characteristics of individualized teaching activities. To this end, a detailed introduction is made to critical factors in the development process of individualized teaching.

Identify learners: to organize and implement individualized teaching, the first and the most important step is to identify learners. Learning supporters must recognize who are learners. The purpose of putting identification of learners in the first place is to fully understand the traits of teaching objects and fully respect the independence of teaching individuals. This is the soul of thought of individualized teaching.

Generally, identification of learners includes two levels: the first one is to identify the characteristics of learners, including basic information, preference and specialty. The second one is to identify needs of learners.

Distinguish learners: to adopt the thought of individualized teaching, it is necessary to classify the learners according to different standards and some variables even in a collective teaching activity. After identifying the learners, the next step is to distinguish them. For the degree of distinguishing, a package of teaching program is usually designed according to the characteristics and learning needs of individual learners, including learning plan support and learning strategy support.

Interaction between teaching and learning: by virtue of developed information technology, learners can be made to participate in continuous dialogues in diversified types, so as to understand learning needs and specific learning interests of learners. At the same time, teachers should also enhance teaching feedback effects, and make further improvement to teaching quality. Besides proper allocation of learners' learning tasks, teachers should also provide learners with convenient feedback channels in the development process of individualized teaching activities, making it convenient for learners to feed back relevant questions to learning supporters ${ }^{[4]}$. Generally, network course platform can be treated as a learning exchange tool. Besides, WeChat or Microblog can also be used to make a survey on satisfaction of teaching activities and to understand learners' learning status, so as to realize better interaction between teaching and learning and perfect individualized teaching activities.

\section{Reflections on Design and Implementation of Individualized Teaching}

Create a liaison net of student management personnel, and effectively implement the student management system: course selection information often involves the following issues: long collection period and insufficient tacit understanding. Therefore, teachers must create a high-efficiency liaison net for teaching affairs personnel, so as to provide non-academic daily management works to students, and realize high-efficiency coordination of students with development of individualized teaching activities.

Implement job standardization and check-up system quantization for teachers: in network individualized teaching, students are guided through short message, telephone, WeChat and other network tools. It is of certain difficulty for accurate statistics of their workload. However, real justice and fairness cannot be realized for assessment on teachers, if without supports from subjective data. Therefore, definite provisions should be made for such assessment. No matter for QQ online time or quantity of instruction posts, there should be the lowest standard ${ }^{[6]}$ so that teachers' working quality and progress can be measured and regularly inspected.

In class and grade division, course division should be used to replace regional division. The system of course division should be used to replace regional division. The application of course division can effectively avoid the issue of one instructor responsible for several classes and forums caused by regional division. At the same time, this method can also reduce the instructor's workload. 
Create supervisory assessment standards for online learning of students: students' online learning conditions should be integrated into assessment standards. By virtue of supports from network background technology, teachers should urge and supervise students to participate in online learning, and require the students to finish stipulated online learning time, course downloading and times of discussion posts before the assessment.

Enhance the construction of network background technology: good network learning condition is served as the support for remote teaching. Therefore, it is necessary for teachers to create and optimize individual learning interface and allow students to feel advantages of individualized teaching in the learning process. Additionally, the selection process of class and course should be further simplified, making it convenient for students to finish their course learning and examinations.

\section{Conclusion}

The purpose of individualized teaching under network environment is to construct an intelligent teaching platform with good performance. Network teaching platform can be used to develop individualized teaching, which can give play to teachers' guiding function, enrich teachers' teaching design under new trend, transform traditional teaching mode, and help students to structure new learning modes. Moreover, such development can also effectively optimize the teaching process and make further improvement to teaching quality and teaching efficiency.

\section{Acknowledgments}

This paper is a subject of Education Department of Hunan Province (Name: Research on Teaching Mode Based on MOOC Innovative Higher Vocational Course; Project No.: 14C0779).

\section{References}

[1] Wang Yu and Zhang Wuhong, Selection, Implementation and Analysis of Network Aided Teaching Platform in Colleges and Universities, E-education Research, 2006, (02);

[2] Li Rumi and Liu Yujing, Connotation and Characteristics of Individualized Teaching, Theory and Practice of Education, 2001, (09);

[3] Wang Jixin, Zhang Yi and Zhang Jingzhong, Principle and Technology of Distance Education [M], Beijing: Peking University Press, 2008;

[4] Zhang Fusheng, Exploration for Practice Strategy of Individualized Teaching under Class Teaching System in Colleges and Universities, Journal of Inner Mongolia Normal University (Educational Science), 2008, (05): 84-86;

[5] Dudeney Hockly and Longman, How to Teach English with Modern Information Technology [M], Beijing: Posts and Telecom Press, 2011;

[6] Huang Xiaona and Wang Biao, Basic Implementation Strategy for Individualized Teaching, Journal of Inner Mongolia Normal University (Educational Science), 2006, (06): 11-13. 